\title{
Levothyroxine in the Older Patient
}

\author{
Salman Razvi
}

Levels of the pituitary hormone thyrotropin (thyroid-stimulating hormone, TSH) tend to run higher in older individuals than in younger adults. As TSH is used to guide replacement with levothyroxine (LT4), older patients may be at risk of over treatment if TSH levels towards the lower part of the standard adult reference range are aimed for. Recent randomised clinical trials have not demonstrated clinical benefit from the use of LT4 in older patients with subclinical hypothyroidism (diagnosed and treated according to standard, adult TSH reference ranges). The results of the recent Study of Optimal Replacement of Thyroxine in the Elderly (SORTED 1) feasibility trial suggest that older hypothyroid patients can be treated using a higher than usual target range for TSH with no apparent adverse effects, at least over the short term.

\section{Thyroid Homeostasis in Older Individuals}

\subsection{Thyroid Homeostasis}

Hypothyroidism is diagnosed when serum thyrotropin (thyroid-stimulating hormone or TSH) is elevated and thyroid hormones are low. The incidence of hypothyroidism increases with age. The reference range limits for serum TSH and thyroid hormones are calculated from measurements obtained from all age groups. However, both the median and $97.5^{\text {th }}$ centile values for TSH increase with age (Fig. 1) [1]. Several studies from various parts of the world have confirmed the increase in serum TSH concentrations with ageing [2-6].

S. Razvi (四)

Translational and Clinical Research Institute, University of Newcastle, Newcastle-upon-Tyne, UK

e-mail: salman.razvi@newcastle.ac.uk 


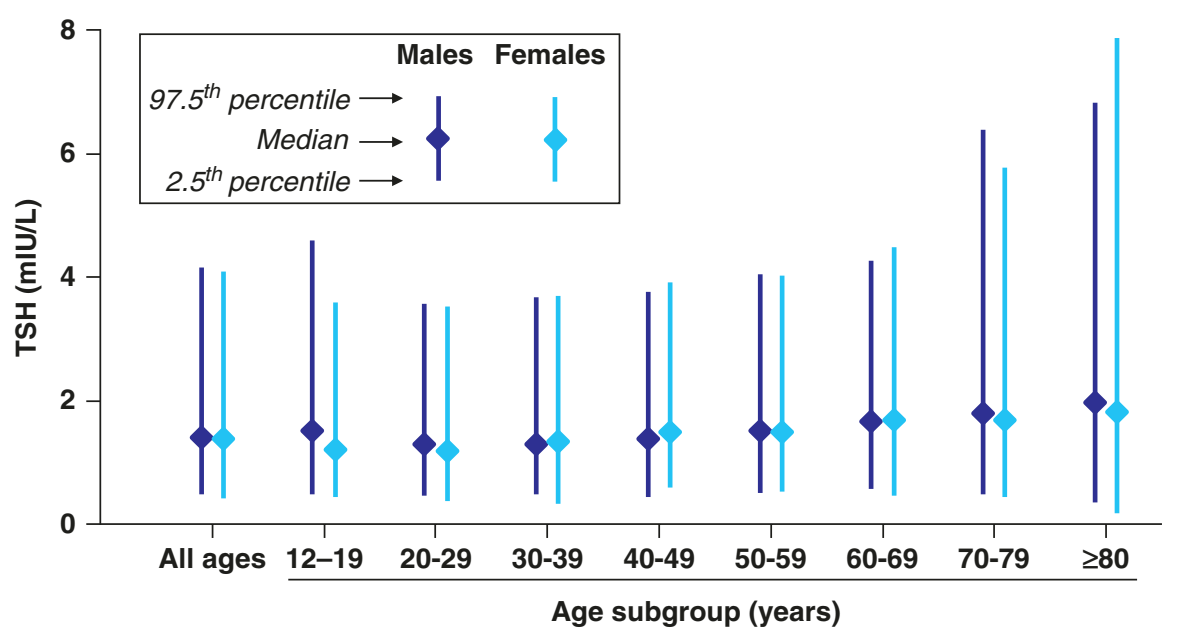

Fig. 1 Medians and $2.5^{\text {th }}-97.5^{\text {th }}$ percentile reference ranges for thyrotropin (TSH) according to age in healthy subjects from a large $(n=13,344)$ population-based study in the USA. Subjects with risk factors for thyroid dysfunction such as pregnancy, oestrogens, androgens, lithium, antithyroid antibodies, and treated thyroid disease were excluded. (Drawn from data presented in Ref. [1])

A study of ambulatory older individuals found that 1 in 40 people had low levels of circulating free thyroxine (FT4) index although thyrotropin levels were normal [7]. A comparison of six of these subjects (mean age 69 years) with six age- and gender-matched subjects with normal FT4 index (also with a normal thyrotropin level) showed that pituitary or hypothalamic dysfunction, pituitary thyrotropin reserve, thyroid reserve, and the biological actions of secreted thyrotropin, did not differ between these groups [7]. Accordingly, the authors concluded that this functional hypothyroidism in some older patients was due to a resetting of the hypothalamic-pituitary-thyroid feedback axis. The mechanisms underlying the increase in TSH with age remain to be elucidated. It does appear, however, that TSH secretion in older people is increased without any change in its bioactivity [8].

\subsection{Thyroid Hormone Levels and Clinical Outcomes}

Lower TSH or higher FT4 levels, including variations of these hormones within the normal range, have been associated with increased risk of mortality [9-12], major adverse cardiovascular events (including myocardial infarction) [13], heart failure [14], frailty [15], and dementia [16, 17] in older populations. Conversely, low-normal FT4 was associated with better mobility and less fatigue, compared with higher levels of FT4, in a study of 602 older euthyroid individuals [18].

Not all studies have associated higher FT4 levels within the normal range with adverse outcomes in older patients, however. Higher thyrotropin and lower FT4 in hospitalised older patients was associated with an increased risk of a composite of morbidity/mortality outcomes (death, admission to the intensive care unit, or 
hospital stay $>18$ days) in a retrospective study [19]. Another study found a higher rate of cognitive decline over time in older women with low-normal vs. high-normal, FT4 [20]. A population-based study demonstrated no association between FT4 levels and cognitive decline in a cohort born in 1912-1914 [10].

Some of these studies suggested little or no significant effect of modest increases in TSH (consistent with subclinical hypothyroidism) on outcomes in this population, even where higher FT4 was associated with an adverse prognosis [12, 14, 17]. Higher TSH in 85 year-old individuals was associated with reduced mortality in the Leiden 85+ study though the authors emphasised the need for further data to corroborate this finding [10]. Another study of a larger number of 85-year-old individuals followed up for a longer period of time than the Leiden study did not confirm the protective association of high TSH with mortality in this age group but nevertheless confirmed that a slightly raised serum TSH was not associated with adverse outcomes [4]. Elsewhere, the risk of heart failure was only increased if TSH was unequivocally abnormal $(<0.1$ or $>10 \mathrm{mIU} / \mathrm{L})$ [14]. A meta-analysis concluded that the excess risk of adverse cardiovascular outcomes in older patients with subclinical hypothyroidism was small, with minimal increased risk in studies of higher quality (relative risks 1.2-1.8 vs. euthyroid individuals) [21]. A second meta-analysis found no association between subclinical hypothyroidism and adverse cardiovascular outcomes in older patients [22].

\section{Therapeutic Use of Levothyroxine in Older Patients with Hypothyroidism}

\subsection{Analyses from Randomised, Placebo-Controlled Trials}

The Thyroid Hormone Replacement for Untreated Older Adults with Subclinical Hypothyroidism Trial (TRUST) randomised 737 adults aged $\geq 65$ years with thyrotropin 4.6-<20 mIU/L and normal FT4 to double-blind treatment with levothyroxine (LT4) or placebo for 1 year [23, 24]. As expected, mean thyrotropin was lower in the LT4 group (3.6 mIU/L) compared with the placebo group $(5.5 \mathrm{mIU} / \mathrm{L})$ at study end. However, there was no effect on the co-primary endpoints in this study (change from baseline in two validated questionnaires specific to thyroid dysfunction: Hypothyroid Symptoms and Tiredness, and the Thyroid-Related Quality-ofLife Patient-Reported Outcome Questionnaire), or on other secondary outcomes. The TRUST trial has been criticised for recruiting participants with mostly low symptom burden [25]. Therefore, it is interesting that a post hoc analysis in subjects with more pronounced symptoms of hypothyroidism at baseline produced a similar lack of clinical benefit of LT4 treatment [26]. Additional sub-analysis from TRUST found no effect of LT4 treatment on cardiac function [27] or bone metabolism [28] in this population.

Pooling the data from two randomised trials, including a subgroup from TRUST, involving a total of 251 patients with subclinical hypothyroidism aged $\geq 80$ years also found no significant effect of LT4 on thyroid symptoms or fatigue, relative to 
placebo [29]. Administration of LT4 for 1 year to patients aged $\geq 65$ years in the primary care setting had no significant effect on cognitive function [30]. A randomised trial in outpatients aged 55 years or over reported a nominally significant effect of LT4 treatment on a composite memory score though there were no benefits of treatments relating to other endpoints, or to health-related quality of life [31]. A metaanalysis published in 2018, which included two studies in patients aged $>65$ years with subclinical hypothyroidism also found no evidence of clinical benefit arising from intervention with LT4 [32].

Hypothyroidism has been associated with an adverse cardiovascular prognosis in some studies (see chapter, "Levothyroxine and the Heart"). Randomisation of 185 patients with subclinical hypothyroidism in a nested subgroup of participants within the TRUST trial aged $\geq 65$ years to LT4 vs. placebo for an average of 18 months had no significant effect on carotid intima-media thickness (a measure of the overall burden of atherosclerosis), however [33].

\subsection{Observational Studies of Levothyroxine in Older Patients with Hypothyroidism}

Observational data in subjects with subclinical hypothyroidism (diagnosed using a cut-off for thyrotropin of $8 \mathrm{mIU} / \mathrm{L}$ ) showed that a similar overall improvement from baseline in health-related quality of life occurred following LT4 treatment in younger ( $<40$ years) and older (>60 years) patients [34]. Both age groups benefitted from improvements in "Emotional Susceptibility" and "Impaired Daily Life" domains; older patients additionally improved their score for "Tiredness" and younger patients improved their score for "Cognitive Complaints". A recent study that included 24 patients with hypothyroidism who were aged $\geq 65$ years and already receiving stable doses of LT4 involved increasing the dose of LT4 by $12.5 \mathrm{mg} /$ day (irrespective of the previous dose) in a single-blind manner for 3 months [35]. This change was sufficient to reduce mean thyrotropin from 1.95 to $0.47 \mathrm{mIU} / \mathrm{L}$. The period of administration of the higher LT4 dose was accompanied by a significant improvement in the Geriatric Depression Scale score, including in patients with a score consistent with clinical depression at baseline, without inducing symptoms of hyperthyroidism. However, the impact of higher doses of LT4 in this age group on long-term outcomes, particularly the risk of atrial fibrillation and osteoporosis, is unknown.

Any severity of hyperthyroidism increases the risk of bone fractures [36], which is a particular concern for the elderly who may be already at risk of age-related osteoporosis [37]. Treatment of women aged $\geq 65$ years with LT4 at a daily dose $>150 \mu \mathrm{g} /$ day was associated with increased fracture risk in an observational study, with the highest risk in women already receiving treatment for osteoporosis [38]. A case-control study in subjects aged $\geq 70$ years also found a dose-related increase in the risk of fractures associated with LT4 treatment [39]. One potential mechanism for the observed adverse events may be due to the risk of inadvertent over-treatment with LT4. In a community-based cohort study, iatrogenic thyrotoxicosis accounted for approximately half of low TSH events, with the highest rates among older women, 
who are vulnerable to atrial fibrillation and osteoporosis [40]. No evidence of any differences in long-term health outcomes are observed when thyrotropin concentrations are maintained within the reference range [41]. Chapter "Levothyroxine and Bone" provides a fuller account of the effects of LT4 on bone health.

\subsection{Managing Elderly Patients with Hypothyroidism: Implications of the SORTED 1 Trial}

The studies reviewed above suggest that the clinical sequelae of hypothyroidism, particularly the subclinical form, appear to be less severe in older vs. younger patients. The randomised evaluations of LT4 have not provided unequivocal evidence for benefit of intervention with LT4 in older patients, especially those with subclinical hypothyroidism [23, 24, 26-29]. It is important to remember that the diagnosis of hypothyroidism and the titration of the LT4 dose were guided in these studies by standard reference ranges for thyrotropin in adults. Given the shift towards higher levels of thyrotropin in elderly populations, the population of TRUST and similar studies probably included individuals who had high TSH relative to the standard adult reference range, who would have been classified as euthyroid using a more age-appropriate reference range [32].

The Study of Optimal Replacement of Thyroxine in the Elderly (SORTED1) study evaluated the clinical consequences of using LT4 to control the level of thyrotropin within a higher range than the usual reference range used to guide LT4 therapy in adults [42-44]. This trial was conducted in 48 elderly ( $\geq 80$ years) patients with pre-existing hypothyroidism whose thyrotropin was well controlled as per the usual local adult reference range $(0.4-4.0 \mathrm{mIU} / \mathrm{L})$. The patients were randomised in a single-blind manner to continuing treatment guided by the standard reference range, or by a higher range $(4.1-8.0 \mathrm{mIU} / \mathrm{L})$ for 6 months.

As expected, the mean thyrotropin level $( \pm \mathrm{SD})$ was higher at 6 months in the higher range group $(6.6 \pm 2.9 \mathrm{mIU} / \mathrm{L})$ than in the standard range group $(1.4 \pm 1.0$ $\mathrm{mIU} / \mathrm{L}$ ); corresponding mean values of other hormones were $16.0 \pm 2.5$ and $19.4 \pm 3.5 \mathrm{pmol} / \mathrm{L}$, respectively, for FT4 and $3.5 \pm 0.5$ and $3.9 \pm 0.4 \mathrm{pmol} / \mathrm{L}$, respectively, for FT3. The mean FT3/FT4 ratio was similar in the higher range $(0.23 \pm 0.04)$ and standard range $(0.21 \pm 0.05)$ groups.

There were no clinically significant differences between groups for mean values of lipid parameters, blood pressures, weight, pulse rate, and a bone resorption marker at study end (Fig. 2). In addition, small and similar changes in group occurred in scores on questionnaires that measured generic and thyroid dysfunction-specific quality of life (EQ-5D and ThyDQoL), or on the risk of falling (falls risk assessment test) or mobility (timed up and go test). The most common allcause adverse events (AE) in the standard and higher range groups were "Feeling more tired" (38\% and 50\%, respectively) and "Problems with balance or mobility" (17\% in each group). No other AE occurred in more than two patients in either group. 


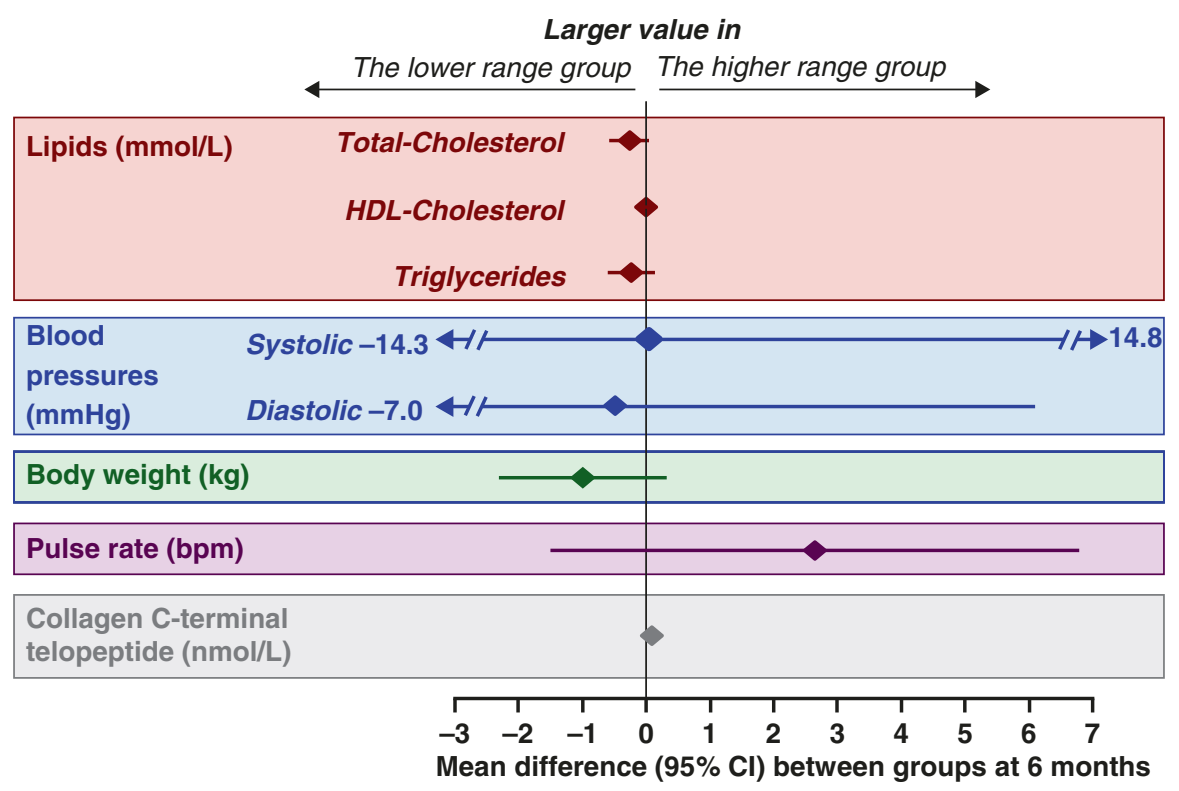

Fig. 2 Effects of randomisation of elderly subjects with subclinical hypothyroidism to a higher or lower target range for thyrotropin on cardiovascular risk factors and a marker of bone resorption in the SORTED 1 Trial. Formal statistical testing was not carried out in this trial, but differences may be considered to be not statistically significant as 95\% CI for mean differences between groups overlap zero for every parameter. $H D L$ high density lipoprotein. See text for definitions of higher and lower range groups. (Drawn from data presented in Ref. [44])

\section{Conclusions}

Thyrotropin levels shift towards higher concentrations in older individuals but current reference ranges are applied uniformly across all age groups. Hence, a significant number of people, particularly in the older age group, are diagnosed with subclinical hypothyroidism and a proportion of these are treated with LT4. The long-term health outcomes and cost-effectiveness of treatment in this particular group of patients is unknown. Furthermore, it also remains unclear whether a higher thyrotropin reference range should be aimed for in older patients on LT4 therapy.

The SORTED 1 trial demonstrated that titrating LT4 therapy to a higher than usual reference range in elderly patients may not adversely affect symptoms of hypothyroidism, or impair quality of life. Moreover, this trial has shown that a suitably powered long-term study is feasible, in order to verify these findings.

Current guidelines for the management of hypothyroidism in adults date back to 2014 , or earlier $[45,46]$. These guidelines acknowledge the shift towards higher levels of thyrotropin as people age (Box 1), as well as the possibility of accepting a higher target value for thyrotropin. There is no unequivocal recommendation to use age-specific reference ranges for thyrotropin in elderly patients with 
hypothyroidism, however. There is growing recognition, though, that the TSH reference range does need to appropriately reflect the age of the individual [47]. The results of recent randomised trials, including SORTED 1 and TRUST, will inform future guidance on the management of the elderly patient with hypothyroidism, probably leading to a less intensive application of LT4 and acceptance of a higher range of thyrotropin levels in elderly patients.

\section{Box 1: Key Recommendations from the USA [45] and European [46] Guidelines on the General Approach for the Management of Hypothyroidism in Elderly Patients}

- Thyrotropin levels tend to be higher in elderly vs. younger people with hypothyroidism, and a higher than usual target level of thyrotropin may be acceptable for an elderly patient $[45,46]$.

- The dose of LT4 to control the thyrotropin level is lower, on average, in older vs. younger subjects, due in part to a lower muscle mass in this population [45].

- Extra vigilance for interference of other medications with the effects of LT4 is necessary for the elderly population, who may be receiving multiple other treatments for comorbid conditions [45].

- Avoidance of iatrogenic thyrotoxicosis due to over treatment with LT4 is a clinical priority in elderly patients with hypothyroidism, especially given the association of higher FT4 levels with adverse outcomes, described above [45].

- Consider monitoring, rather than intervening with LT4, for very elderly (>80 years) patients with subclinical hypothyroidism [46].

- Consider a "start low, go slow" approach to administering LT4 to elderly patients $[45,46]$.

\section{References}

1. Hollowell JG, Staehling NW, Flanders WD, et al. Serum TSH, T(4), and thyroid antibodies in the United States population (1988 to 1994): National Health and Nutrition Examination Survey (NHANES III). J Clin Endocrinol Metab. 2002;87:489-99.

2. Ceresini G, Lauretani F, Maggio M, et al. Thyroid function abnormalities and cognitive impairment in elderly people: results of the Invecchiare in Chianti study. J Am Geriatr Soc. 2009;57:89-93.

3. Yeap BB. Hormones and health outcomes in aging men. Exp Gerontol. 2013;48:677-81.

4. Pearce SH, Razvi S, Yadegarfar ME, et al. Serum thyroid function, mortality and disability in advanced old age: the Newcastle 85+ study. J Clin Endocrinol Metab. 2016;101:4385-94.

5. Wang D, Li D, Guo X, et al. Effects of sex, age, sampling time, and season on thyroidstimulating hormone concentrations: a retrospective study. Biochem Biophys Res Commun. 2018;506:450-4. 
6. Surks MI, Hollowell JG. Age-specific distribution of serum thyrotropin and antithyroid antibodies in the US population: implications for the prevalence of subclinical hypothyroidism. $\mathrm{J}$ Clin Endocrinol Metab. 2007;92:4575-82.

7. Lewis GF, Alessi CA, Imperial JG, Refetoff S. Low serum free thyroxine index in ambulating elderly is due to a resetting of the threshold of thyrotropin feedback suppression. J Clin Endocrinol Metab. 1991;73:843-9.

8. Jansen SW, Akintola AA, Roelfsema F, et al. Human longevity is characterised by high thyroid stimulating hormone secretion without altered energy metabolism. Sci Rep. 2015;5:11525.

9. Ceresini G, Marina M, Lauretani F, et al. Relationship between circulating thyroid-stimulating hormone, free thyroxine, and free triiodothyronine concentrations and 9-year mortality in euthyroid elderly adults. J Am Geriatr Soc. 2016;64:553-60.

10. Gussekloo J, van Exel E, de Craen AJ, Meinders AE, Frölich M, Westendorp RG. Thyroid status, disability and cognitive function, and survival in old age. JAMA. 2004;292:2591-9.

11. Yeap BB, Alfonso H, Hankey GJ, et al. Higher free thyroxine levels are associated with all-cause mortality in euthyroid older men: the health in men study. Eur J Endocrinol. 2013;169:401-8.

12. Waring AC, Arnold AM, Newman AB, Bùzková P, Hirsch C, Cappola AR. Longitudinal changes in thyroid function in the oldest old and survival: the cardiovascular health study allstars study. J Clin Endocrinol Metab. 2012;97:3944-50.

13. Golledge J, Hankey GJ, Almeida OP, Flicker L, Norman PE, Yeap BB. Plasma free thyroxine in the upper quartile is associated with an increased incidence of major cardiovascular events in older men that do not have thyroid dysfunction according to conventional criteria. Int $\mathrm{J}$ Cardiol. 2018;254:316-21.

14. Nanchen D, Gussekloo J, Westendorp RG, et al. Subclinical thyroid dysfunction and the risk of heart failure in older persons at high cardiovascular risk. J Clin Endocrinol Metab. 2012;97:852-61.

15. Yeap BB, Alfonso H, Chubb SA, et al. Higher free thyroxine levels are associated with frailty in older men: the health in men study. Clin Endocrinol (Oxf). 2012;76:741-8.

16. Yeap BB, Alfonso H, Chubb SA, et al. Higher free thyroxine levels predict increased incidence of dementia in older men: the health in men study. J Clin Endocrinol Metab. 2012;97:E2230-7.

17. Eskelinen SI, Vahlberg TJ, Isoaho RE, Löppönen MK, Kivelä SL, Irjala KM. Associations of thyroid-stimulating hormone and free thyroxine concentrations with health and life satisfaction in elderly adults. Endocr Pract. 2007;13:451-7.

18. Simonsick EM, Chia CW, Mammen JS, Egan JM, Ferrucci L. Free thyroxine and functional mobility, fitness, and fatigue in euthyroid older men and women in the Baltimore Longitudinal Study of Aging. J Gerontol A Biol Sci Med Sci. 2016;71:961-7.

19. Mingote E, Meroño T, Rujelman R, et al. High TSH and low T4 as prognostic markers in older patients. Hormones (Athens). 2012;11:350-5.

20. Volpato S, Guralnik JM, Fried LP, Remaley AT, Cappola AR, Launer LJ. Serum thyroxine level and cognitive decline in euthyroid older women. Neurology. 2002;58:1055-61.

21. Ochs N, Auer R, Bauer DC, et al. Meta-analysis: subclinical thyroid dysfunction and the risk for coronary heart disease and mortality. Ann Intern Med. 2008;148:832-45.

22. Razvi S, Shakoor A, Vanderpump M, Weaver JU, Pearce SH. The influence of age on the relationship between subclinical hypothyroidism and ischemic heart disease: a metaanalysis. $\mathrm{J}$ Clin Endocrinol Metab. 2008;93:2998-3007.

23. Stott DJ, Gussekloo J, Kearney PM, et al. Study protocol; thyroid hormone replacement for untreated older adults with subclinical hypothyroidism - a randomised placebo controlled trial (TRUST). BMC Endocr Disord. 2017;17:6.

24. Stott DJ, Rodondi N, Kearney PM, et al. Thyroid hormone therapy for older adults with subclinical hypothyroidism. N Engl J Med. 2017;376:2534-44.

25. Razvi S, Peeters R, Pearce SHS. Thyroid hormone therapy for subclinical hypothyroidism. JAMA. 2019;321:804. 
26. de Montmollin M, Feller M, Beglinger S, et al. L-thyroxine therapy for older adults with subclinical hypothyroidism and hypothyroid symptoms: secondary analysis of a randomized trial. Ann Intern Med. 2020;172:709-16.

27. Gencer B, Moutzouri E, Blum MR, et al. The impact of levothyroxine on cardiac function in older adults with mild subclinical hypothyroidism: a randomized clinical trial. Am J Med. 2020;133:848-856.e5.

28. Gonzalez Rodriguez E, Stuber M, Del Giovane C, et al. Skeletal effects of levothyroxine for subclinical hypothyroidism in older adults: a TRUST randomized trial nested study. J Clin Endocrinol Metab. 2020;105:dgz058.

29. Mooijaart SP, Du Puy RS, Stott DJ, et al. Association between levothyroxine treatment and thyroid-related symptoms among adults aged 80 years and older with subclinical hypothyroidism. JAMA. 2019;322:1-11.

30. Parle J, Roberts L, Wilson S, et al. A randomized controlled trial of the effect of thyroxine replacement on cognitive function in community-living elderly subjects with subclinical hypothyroidism: the Birmingham Elderly Thyroid study. J Clin Endocrinol Metab. 2010;95:3623-32.

31. Jaeschke R, Guyatt G, Gerstein H, et al. Does treatment with L-thyroxine influence health status in middle-aged and older adults with subclinical hypothyroidism? J Gen Intern Med. 1996;11:744-9.

32. Feller M, Snel M, Moutzouri E, et al. Association of thyroid hormone therapy with quality of life and thyroid-related symptoms in patients with subclinical hypothyroidism: a systematic review and meta-analysis. JAMA. 2018;320:1349-59.

33. Blum MR, Gencer B, Adam L, et al. Impact of thyroid hormone therapy on atherosclerosis in the elderly with subclinical hypothyroidism: a randomized trial. J Clin Endocrinol Metab. 2018;103:2988-97.

34. Recker S, Voigtländer R, Viehmann A, et al. Thyroid related quality of life in elderly with subclinical hypothyroidism and improvement on levothyroxine is distinct from that in young patients (TSAGE). Horm Metab Res. 2019;51:568-74.

35. Moon JH, Han JW, Oh TJ, et al. Effect of increased levothyroxine dose on depressive mood in older adults undergoing thyroid hormone replacement therapy. Clin Endocrinol (Oxf). 2020;93:196-203.

36. Blum MR, Bauer DC, Collet TH, et al. Subclinical thyroid dysfunction and fracture risk: a meta-analysis. JAMA. 2015;313:2055-65.

37. Swedish Council on Health Technology Assessment. Osteoporosis-prevention, diagnosis and treatment: a systematic review [Internet]. Stockholm: Swedish Council on Health Technology Assessment (SBU); Oct 2003. SBU Yellow Report No. 165/1+2. Available at https://www. ncbi.nlm.nih.gov/books/NBK447989/. Accessed Jul 2020.

38. Ko YJ, Kim JY, Lee J, et al. Levothyroxine dose and fracture risk according to the osteoporosis status in elderly women. J Prev Med Public Health. 2014;47:36-46.

39. Turner MR, Camacho X, Fischer HD, et al. Levothyroxine dose and risk of fractures in older adults: nested case-control study. BMJ. 2011;342:d2238.

40. Mammen JS, McGready J, Oxman R, Chia CW, Ladenson PW, Simonsick EM. Thyroid hormone therapy and risk of thyrotoxicosis in community-resident older adults: findings from the Baltimore Longitudinal Study of Aging. Thyroid. 2015;25:979-86.

41. Thayakaran R, Adderley NJ, Sainsbury C, et al. Thyroid replacement therapy, thyroid stimulating hormone concentrations, and long term health outcomes in patients with hypothyroidism: longitudinal study. BMJ. 2019;366:14892.

42. Wilkes S, Pearce S, Ryan V, Rapley T, Ingoe L, Razvi S. Study of Optimal Replacement of Thyroxine in the EIDerly (SORTED): protocol for a mixed methods feasibility study to assess the clinical utility of lower dose thyroxine in elderly hypothyroid patients: study protocol for a randomized controlled trial. Trials. 2013;14:83. 
43. Razvi S, Ingoe L, Ryan V, Pearce SH, Wilkes S. Study of Optimal Replacement of Thyroxine in the Elderly (SORTED)—results from the feasibility randomised controlled trial. Thyroid Res. 2016;9:5.

44. Razvi S, Ryan V, Ingoe L, Pearce SH, Wilkes S. Age-related serum thyroid-stimulating hormone reference range in older patients treated with levothyroxine: a randomized controlled feasibility trial (SORTED 1). Eur Thyroid J. 2020;9:40-8.

45. Jonklaas J, Bianco AC, Bauer AJ, et al. Guidelines for the treatment of hypothyroidism: prepared by the American Thyroid Association task force on thyroid hormone replacement. Thyroid. 2014;24:1670-751.

46. Pearce SH, Brabant G, Duntas LH, et al. 2013 ETA guideline: management of subclinical hypothyroidism. Eur Thyroid J. 2013;2:215-28.

47. Cappola AR. The thyrotropin reference range should be changed in older patients. JAMA. 2020 (advance publication online, https://doi.org/10.1001/jama.2019.14728).

Open Access This chapter is licensed under the terms of the Creative Commons Attribution 4.0 International License (http://creativecommons.org/licenses/by/4.0/), which permits use, sharing, adaptation, distribution and reproduction in any medium or format, as long as you give appropriate credit to the original author(s) and the source, provide a link to the Creative Commons license and indicate if changes were made.

The images or other third party material in this chapter are included in the chapter's Creative Commons license, unless indicated otherwise in a credit line to the material. If material is not included in the chapter's Creative Commons license and your intended use is not permitted by statutory regulation or exceeds the permitted use, you will need to obtain permission directly from the copyright holder.

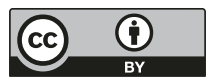

